\title{
Eye movement desensitization and reprocessing
}

\author{
Hatice Kolay (10)
}

\begin{abstract}
Eye movement desensitization and reprocessing (EMDR) is a psychotherapy technique involving desensitization and repetitively processing events to alleviate negative cognitions, emotions, and bodily sensations of the client, it was first described as a therapeuctic method in Shapiro's work . Positive outcomes in post-traumatic stress disorder patients have especially increased the interest in EMDR. Its basis lies in the concepts of psychodynamic, cognitive and behavioral approaches and also focuses on processing information predicated on the adaptive information processing model. Eye movement desensitization and reprocessing, applied through structured sessions, has appropriate procedures and protocols for cases. According to its techniques, it bears inspiration from the theories on which it is based. Eye movement desensitization and reprocessing application has eight phases, each with a different purpose. It has taken its place as a therapeutic approach drawing interest in Turkey.

Keywords: Brain, eye movement desensitization and reprocessing, post-traumatic stress disorder, psychotherapy, trauma.
\end{abstract}

In recent years, eye movement desensitization and reprocessing (EMDR) has become one of the top subjects of interest in the field of psychological counseling. Undoubtedly, one of the points that enabled EMDR to attract such attention was its use of eye movements. Eye movement desensitization and reprocessing therapy initially emerged as a technique based on desensitization through eye movements and was used in many studies. However, Shapiro, who later developed the technique, adapted the EMDR technique into a psychotherapy theory based on psychodynamic, cognitive, and behavioral counseling theories. It would be accurate to say that EMDR therapy, which carries techniques and perspectives of starting point theories, has a wide field of application.

Eye movement desensitization and reprocessing therapy has developed from the 1990s until now, and has spread to many countries at this point. It emerged in our country with the 1999 earthquake and its use in post-traumatic stress disorder (PTSD) cases. The Turkish Eye Movement Desensitization and Reprocessing Association has existed since 2007. This association provides EMDR education and trains EMDR therapists. While EMDR has proven its success in many areas, it has especially attracted attention in PTSD. Eye movement desensitization and reprocessing therapy, which is very successful in PTSD cases, not only uses the therapeutic power of eye movements, but also cognitively contributes to coping with new perspectives and negative automatic thoughts. Therefore, post-traumatic advancement is rapid and effective. Examination of EMDR techniques has shown that cognitive techniques are dominant. In PTSD, the person's making sense of and reprocessing the event must be built upon a realistic foundation, requiring active working process with emotions. Therefore, EMDR is an effective therapy technique for PTSD, as it uses active coping abilities with psychoanalytic, cognitive, and behavioral concepts. 


\section{WHAT IS EMDR}

Eye movement desensitization and reprocessing is a therapy approach used in an increasing variety of fields, which was especially proven effective in PTSD by Shapiro in 1995. ${ }^{[1]}$ In terms of ease of use in the literature, Eye Movement Desensitization and Reprocessing is abbreviated as EMDR. Eye movement desensitization and reprocessing is based on the therapist moving their finger in a systematic manner from right to left, and the client following these movements with their eyes. However, it can also be performed by giving dual stimuli, not just visual stimulus, but also hearing and touch. According to Shapiro, although its name derives from eye movements, this approach also includes the content of other therapeutic approaches. ${ }^{[1]}$

What separates EMDR from other therapy methods is that while systematic and two-way stimuli are given, the client concentrates on images of the traumatic event. ${ }^{[2]}$

Eye movement desensitization and reprocessing is based on three premises. The first is that beneath pathologic conditions lie traumatic incidents which are not adequately processed by the brain. The second is that rhythmic stimuli can provide treatment of trauma. Lastly, EMDR can be applied in all problems related to generalizable trauma, especially PTSD. ${ }^{[3]}$

\section{THE RISE OF EMDR}

Shapiro describes the origin of EMDR in the book, Getting Past Your Past: Take Control of Your Life with Self-Help Techniques from EMDR Therapy. One day, when taking a walk in the park, she contemplated how the disturbing thoughts in her mind had disappeared and realized that, at that moment, she was rapidly moving her eyes from right to left. ${ }^{[4]}$ After her initial observation in 1987, Francine Shapiro conducted her first controlled clinical study in 1988 . The subject has continued to be the subject of many studies since $1988 .^{[5]}$

\section{Adaptive information processing model}

Eye movement desensitization and reprocessing is based on the Adaptive Information Processing model. According to this model, our experiences are organized into networks, which form the basis for our attitudes and perceptions, while new experiences are evaluated with the help of these networks. ${ }^{[6]}$ According to this model, a healthy individual evaluates new experiences with the help of the network scheme, and after assimilating information that is deemed useful, the rest is discarded. This occurs automatically every time the individual encounters a new experience. Functional unstored memories form the basis of problems. ${ }^{[6]}$

\section{FIELDS OF EMDR USE IN TURKISH RESEARCH}

\section{Post-traumatic stress disorder}

Post-traumatic stress disorder and its associated "trauma" aspect has been defined in the Diagnostic and Statistical Manual of Mental Disorders, Third Edition (DSM-III). ${ }^{[7]}$ After the traumatic event, the individual exerts various reactions to defend themselves at the end of a traumatic incident. While these reactions are considered normal to an extent, they are evaluated as pathological after a certain point. While PTSD is evaluated within anxiety disorders, it is addressed in The Diagnostic and Statistical Manual of Mental Disorders, Fifth Edition (DSM-V) under traumarelated disorders. ${ }^{[8]}$

\section{Posttraumatic growth}

The concept of posttraumatic growth is the person's strides to regain functionality in life after experiencing trauma emphasized that posttraumatic growth was the person's increased levels of compliance, functionality, and awareness. ${ }^{\left[{ }^{[]}\right.}$Many techniques are used in the recovery period of $\mathrm{PTSD}$, one of which is EMDR therapy.

According to EMDR, trauma is a knot nonfunctionally stored in memory. Since the memory is stored in a nonfunctional manner, it causes nonfunctional responses. It also negatively affects the person's perception of self. This nonfunctionally stored memory consists of emotions, thoughts, and sensations. Sometimes new experiences may be neurobiologically unprocessed according to memory networks. The individual's reexperiencing the traumatic event over and over may be because it has not been processed. This causes the traumatic event to be processed and gain functionality. ${ }^{[5]}$ 


\section{Specific phobia}

Specific phobia is the state of extreme fear against a particular objective or situation, despite knowing that it is illogical. ${ }^{[10]}$ Five different groups have been identified in the classification of specific phobias including animal-natural-environment, blood-injection-injury, situational and other.

According to Shapiro, phobia includes fear of the fear. It was observed that initial traumatic experiences were traumatic first experiences which were not functionally stored. According to Shapiro, many phobias can be treated with simple EMDR protocols. ${ }^{[6]}$

\section{Schizophrenia}

Considering the lives of schizophrenics, their probability of encountering traumatic life events is $50-98 \%$. It is also known that childhood trauma increases the risk of psychosis by three times. According to these factors, the coexistence of PTSD and psychosis is high. In the coexistence of PTSD and psychotic disorders, EMDR allows recovery of positive symptoms, anxiety symptoms, and low self-perception..$^{[5]}$

\section{Attention Deficit Hyperactivity Disorder (ADHD)}

Neurobiological factors in ADHD formation include problems in transportation of stimuli causing irregularity in brain activity. ${ }^{[2]}$

Bal $^{[2]}$ applied EMDR and cognitive behavioral therapy (CBT) in ADHD patients and found that EMDR was more effective than CBT. The study concluded that EMDR application was more effective than $\mathrm{CBT}$ in patients with mental disability.

According to the data in this study, EMDR therapy method allowed students to gain progress in attention behavioral level.

\section{Vaginismus}

Studies on adult women with vaginismus who experienced sexual trauma during childhood demonstrated that EMDR provided reduced symptoms or recovery in trauma symptoms. ${ }^{[11]}$

Torun $^{[11]}$ investigated the applicability of EMDR technique in sexual trauma related vaginismus in two case reports. After EMDR treatment, no vaginismus symptoms were observed and after subsequent follow-up sessions, it was observed that the couple did not experience any sexual problems. This case report study found that EMDR was an effective treatment method for vaginismus.

\section{Fibromyalgia}

Fibromyalgia syndrome (FMS) is a disorder characterized by body pain of unknown cause. ${ }^{[12]}$ Many studies have revealed that individuals with this syndrome have a high rate of experiencing traumatic and stressful life events. In studies by Kavakçı, Kaptanoğlu, Kuğu and Doğan, the pain protocol of EMDR, which lasted 12 weeks, was applied to 38 patients with chronic pain, including patients with FMS. At the end of treatment, they reported a significant improvement in patients' complaints, a significant decrease in the amount of medication used for pain, and a significant improvement in their quality of life, and significant decrease in depression and anxiety scores. ${ }^{[12]}$

\section{PHASES OF EMDR}

Eye movement desensitization and reprocessing application consists of eight phases. The first and second phases can occur in one session each, while the rest of the phases may take longer. ${ }^{[12]}$ The phases and general details of the phases are described below.

\section{History and treatment planning}

This phase consists of taking history and planning treatment of the client. The therapist meets the client and takes a general history. The client's trauma and life conditions are analyzed. The client is listened to as carefully as possible. ${ }^{[1]}$

\section{Planning}

At this phase, the client is informed on many subjects such as the basics of EMDR therapy, the principles of application, and its goal to establish a therapeutic relationship. Introducing EMDR to the client is important both for the client's involvement in the process and approval from the client. After the client gives consent, basic eye movements are demonstrated to the client. In addition, relaxation and safe ground exercises are taught so that they can be used in traumatic moments in the following sessions. ${ }^{[1]}$ 


\section{Assessment}

When this phase is reached, the client is asked to form a visual image. The client's opinions of the traumatic event are taken. The clients' views and how they evaluate themselves as a result of the traumatic experience are discussed. Negative selfassessments and functional and positive status of this assessment are determined. Then, the client is asked to estimate how true a positive belief feels on a scale of 1 to 7 and also assess how true a negative belief feels on a scale of 1 to 10 . The client is then asked to focus on and determine the sensations in their body while overcoming the traumatic event. ${ }^{[1]}$

\section{Desensitization}

During the desensitization phase, the client is asked to imagine the disturbing experience, and to focus on his negative beliefs and bodily sensations about this experience. Meanwhile, the counselor begins conducting two-way systematic stimuli with either sight, hearing, or touch. Usually, the sense of sight is used by aiming to provide desensitization with systematic eye movements. The client follows the movements of the therapist's finger with their eyes or right-left eye movements are stimulated by using recently developed stimulus tools. ${ }^{[1]}$ A series of 24 eye movements are called an eye movement sequence, and after each eye movement sequence, the client is asked to evaluate their stress level and score it on a scale of $0-10$. This process continues until the stress level goes down to 0 or $1 .^{[1]}$ Although the session duration is 90 minutes, the number of desensitization sessions varies from client to client. ${ }^{[6]}$

\section{Installation}

The purpose of this phase is to combine traumatic experience and functional thinking. When it comes to the installation phase, the psychological therapist reminds the client of the functional belief identified in Phase 3 which is evaluated between 1-7. Score of 7 means "fully valid". The counselor tries to bring the client to this phase. ${ }^{[6]}$

\section{Body scan}

This phase involves bodily sensations. The client is asked to imagine the traumatic experience and focus on their body. If a discomfort is felt in the body at this time, the eye movement sequences are continued and the disturbing sensation is attempted to be eliminated. ${ }^{[6]}$

\section{Closure}

The closure aims for the client to leave the session with a sense of trust. ${ }^{[6]}$ The psychological therapist can end the session by giving the client relaxation exercises or safe-place exercises. The main goal of closure is that the client has positive affect and is ready. ${ }^{[6]}$

\section{Reevaluation}

At the reevaluation phase, the achievements of the other phases are evaluated in detail. As the sessions progress, the previous session is evaluated at the start of the session. In the last session, the traumatic event is reconsidered and the change in the client is evaluated. ${ }^{[2]}$

\section{EMDR PROCEDURES AND PROTOCOLS}

Eye movement desensitization and reprocessing therapy sessions are a planned approach consisting of step by step procedures and protocols. Although these are generally applied to all clients, they are individually adjusted according to the client. ${ }^{[6]}$

\section{Declaration of conflicting interests}

The authors declared no conflicts of interest with respect to the authorship and/or publication of this article.

\section{Funding}

The authors received no financial support for the research and/or authorship of this article.

\section{REFERENCES}

1. Denizli S. Göz hareketleriyle duyarsızlaştırma ve yeniden işleme: Yaklaşımın etkililiği ve bugünkü durumu. Ege Eğitim Dergisi 2008;2:79-92.

2. Bal F. Bilişsel davranışçı ve EMDR terapi yöntemlerinin dikkat eksikliği üzerindeki etkinliğinin incelenmesi, SSS Journal 2018;4:5245-58.

3. Kışlak ŞT. Kaygı duyarlığını azaltmada göz hareketleriyle duyarsızlaştırma ve yeniden işleme (EMDR) Tedavisi. Türk Psikoloji Dergisi 2004;19:49-65.

4. Shapiro F. EMDR terapisi teknikleri ile acı anıları silmek. Çeviri editörü: Gülfidan F. İstanbul: Kuraldışı Yayıncllk; 2018. s. 27-45. 
5. Kavakcı Ö, Doğan O, Kuğu N. EMDR (eye movement desensitization and reprocessing): a different option in psychotherapy. Dusunen Adam The Journal of Psychiatry and Neurological Sciences 2010;23:195-205.

6. Shapiro F. EMDR: Göz hareketleriyle duyarsızlaştırma ve yeniden işleme temel prensipler, protokoller ve prosedürler. Çeviri editörleri: Şaşzade M, Sansoy I. İstanbul: Okuyanus Yayınları 2018. s. 111-384.

7. Özen F, Aydın H. Travma sonrası stres bozukluğu. Klinik Psikiyatri 1999;1:34-41.

8. Özten E, Sayar GH. Eşik altı travma sonrası stres bozukluğu. Psikiyatride Güncel Yaklaşımlar 2015;7:348-55.
9. Ezerbolat M, Yilmaz Özpolat AG. Travma sonrası büyüme: Travmaya iyi yönünden bakmak. Kriz Dergisi 2016;24:20-8.

10. Demirci OO, Sağalııı E, Yıldırım A. Özgül fobinin göz hareketleri ile duyarsızlaştırma ve yeniden işleme yöntemi ile tedavisi: Bir olgu sunumu. Klinik Psikiyatri 2015;18:124-9.

11. Torun F. Vajinismusun EMDR yöntemi ile tedavisi: İki olgu sunumu. Türk Psikiyatri Dergisi 2010;21:243-8.

12. Kavakçı Ö, Kaptanoğlu E, Kuğu N, Doğan O. EMDR fibromiyalji tedavisinde yeni bir seçenek olabilir mi? Olgu sunumu ve gözden geçirme. Klinik Psikiyatri 2010;13:143-51. 